\title{
The Impact of Different Antitrust Laws on the Actions of Cartels
}

\author{
Jue-Shyan Wang, Yi-Shao Chen \\ Department of Public Finance, National Chengchi University, Taipei, Chinese Taipei \\ Email: jswang@nccu.edu.tw \\ Received October 15, 2012; revised November 13, 2012; accepted December 10, 2012
}

\begin{abstract}
The issues about antitrust laws are getting much attention nowadays. And many countries over the world adopt leniency policies to control the actions of cartels. We used a game-theoretical model to discuss the equilibrium of cartels under different antitrust laws. And we modify the model of Blum et al. [1] to analyze the equilibriums of firms under the different mechanisms of leniency policies. We find out that the value of fine will affect the existence of a cartel, and the recognitions of legitimacies for cartels are important as well. When the antitrust authorities ask firms to propose appliances in advance to let the cartels be legal, firms would incline not to become a cartel. It's quite different from the other mechanism which firms can confess to the antitrust authorities after they've already become a cartel.
\end{abstract}

Keywords: Cartel; Leniency Policy; Bayesian Nash Equilibrium

\section{Introduction}

Much literature discussed about the antitrust laws which are not all the same among the countries. The USA is the pioneer to set the antitrust law. After that, so many other countries passed legislation of antitrust laws, one after another. Antitrust law is also called competition law. It's often used to keep the market from unfair competition or stop firms forming a private cartel. A cartel is a formal agreement among competing firms. Firms get together to set their business strategies in order to raise their benefit. In this way, firms can definitely expand their magnitude and get abnormal profit by reducing competition. But these actions can be harmful for the social welfare. In order to regulate or forbid collusion (also called cartel agreement), the antitrust authorities would set their own antitrust laws in view of their own circumstances. Leniency policy is a new policy that has been applied in recent years.

In this paper, we used a game-theoretical model to analyze the equilibrium belonging to cartel. It isn't always bad for social welfare when there are cartels in society. Sometimes, cartels may be good for the whole society. Hence, the antitrust authorities have to find their own solutions to raise the whole social welfare.

In Europe commission (EC), if firms have collusive agreement and become a cartel, they will be forbidden by the Cartel office unless the actions of collusion are helpful for production or distribution of goods. At the same time, cartels should improve the development of technique and economy and ensure that consumer's welfare is guaranteed definitely. That is to say, firms won't be punished if the collusion is beneficial for consumers' welfare as well as the whole social welfare. And it wouldn't be necessary to submit an appliance in advance in the most European countries. This kind of mechanism in Europe is much similar with the United States. Antitrust division has a power of prosecutorial discretion which means they can process the cases as they want. Hence there would be case selection. If the antitrust authorities think the cartels are harmless to the society, they may ignore and drop the cases. The reason is that they think they don't have enough resource to handle all the cases. In Taiwan, antitrust authority is called Fair Trade Commission. Collusion won't be allowed basically, but under some particular circumstances, firms can also exempt from the Fair trade Act. The most obvious difference between American law (or EC's law) and Taiwanese law is that firms must submit appliance in advance no matter what situations in Taiwan. If not, cartels are always illegal without registration. Even if the collusion is beneficial to the whole social welfare, it's surely unacceptable in Taiwan.

In order to control the actions of cartels, the antitrust authorities introduce a mechanism to influence the strategies that firms would take. Antitrust law has a kind of reward program which we call leniency policy or leniency program. Leniency policy was introduced for the first time by the United States in 1978 that allowed firms to be the whistle blowers and to have a reduction of fine 
payment under some specific conditions. Sometimes the whistle blowers can exempt from all the punishment. At first, only a few firms applied for this leniency program because it wasn't very transparent and it brought some kind of uncertainties. Consequently, it was revised significantly in 1993. Leniency policy is really a key factor for the cartel office to affect the actions of firms. So the legislations of this kind of laws become much more and more important.

Consequently, we discuss whether the equilibrium derived from the game-theoretical model, fit the antitrust law or not. And we will measure the welfare from the standpoint of the whole society.

Motta and Polo [2] concluded that the government should let the confessors or the whistle blowers have the full immunity from the punishment. Ellis and Wilson [3] thought the concentration of market is an important element to affect cartel. The antitrust authority has to create some motivations for firms to cheat on others. Spagnolo [4] thought super high reward for the first whistle blower is an incentive to squeal. Aubert et al. [5] discussed not only the ordinary leniency policy which contains reduced fines and positive reward, but also argued that rewarding individuals in the firms, including employees of firms may be useful. Chavda and Jegers [6] thought if the impunity is granted for firms, cheating is the most profitable way for them. To fight with the collusive behavior, the antitrust authorities use combinations of severe punishment and fine exemptions. We call it "carrot and stick policy". Blum et al. [1] challenged the contemporary view that standard leniency privilege is incentive compatible to increase competition. They thought leniency policy is a preemptive strike for firms against competetors when cartels become unstable. The defectors may have more economical privilege in the future. Accordingly, if the leniency policy would lead to more competetion in the market, the policy should be welcomed by the national cartel offices.

In this paper, we would discuss about the impact of different antitrust laws on firms. For example, the antitrust authorities ask firms hand in their appliance before-hand to be legal. Or after-the-fact policy which means cartels can be legal as they are good for the whole society even they don't tell the antitrust authorities first. Blum et al. [1] only categorized the games corresponded the areas in the figures, but we directly solved Bayesian Nash Equilibriums of the cartel game. And furthermore, we discussed the degree of difficulty to form cartels under different national antitrust laws.

\section{The Model}

We based on the model of Blum et al. [1] and we did some reformation. Let's set a model of a cartel with two suppliers in the market, player 1 and player 2. The two suppliers are two firms competing with each other. We assume the firms as homogeneous under the general condition, which means the two firms have the same condition of abilities. There are two kinds of situation for firms to react. Firms can comply, which means the two firms adhere to their cartel agreement. Still, firms can defect, which means one or both of them would squeal to the antitrust authorities.

As for the antitrust authorities, they must want the leniency policy to be useful and be attractive for any party to defect. So, leniency privilege must be known for every player. Moreover, antitrust authorities would prefer to take side of the whole society to maximize social welfare.

Let's begin to introduce the meaning of parameters: We assume the market reward is $\pi$, the cartel surplus is $c$, the fine for a proven cartel is $f$, and the leniency reduction is $w$. The first mover has an additional advantage, $a$, it can be regard as an improved cost structure or getting an increased market share. If leniency privilege is not only for the first mover but also granted to the subsequent confessing parties, the authority may offer the confessors a reward, $z$, instead of $w$. As we can see, $Z$ applies to the second confessor in the model, and $z \in[0, w]$. And note that $z$ is non-negative because it would reduce the fine, $f$. And $p$ is the probability of a confession being processed by the antitrust authority which might be less than 1 because of work overloaded. $p \in(0,1)$.

And the normal form of the game is presented in Table 1 .

If the equilibrium is $\left(1^{\prime}\right)$, it means there is a stable cartel. If the equilibrium is ( $\left.2^{\prime}\right)$ or ( $\left.3^{\prime}\right)$, it means one part of them defects and be the crown witness. If the equilibrium is (4'), which means that they both defect and there would be a price war and cartel fine.

In Table 1, the definitions of the symbols are as below:

$$
\begin{aligned}
A_{1} & \equiv \pi+c, A_{2} \equiv \pi+c \\
B_{1} & =p(\pi+a-f+w)+(1-p)(\pi+c) \\
& =p(a+w-f-c)+\pi+c \\
B_{2} & =p(\pi-f+z)+(1-p)(\pi+c) \\
& =p(z-f-c)+\pi+c \\
C_{1} & =p(\pi-f+z)+(1-p)(\pi+c) \\
& =p(z-f-c)+\pi+c \\
C_{2} & =p(\pi+a-f+w)+(1-p)(\pi+c) \\
& =p(a+w-f-c)+\pi+c
\end{aligned}
$$




$$
\begin{aligned}
D_{1}= & p[p(\pi-f+w)+(1-p)(\pi+a-f+w)] \\
& +(1-p)[p(\pi-f+z)+(1-p)(\pi+c)] \\
= & p^{2}(f+c-a-z)+p(a+w+z-2 f-2 c)+\pi+c \\
D_{2}= & p[p(\pi-f+w)+(1-p)(\pi+a-f+w)] \\
& +(1-p)[p(\pi-f+z)+(1-p)(\pi+c)] \\
= & p^{2}(f+c-a-z)+p(a+w+z-2 f-2 c)+\pi+c
\end{aligned}
$$

We didn't only care about the equilibrium payoff of two firms, but also put emphasis on the consumers' surplus. That's because we take the stance of the social welfare. And we will discuss it in the later section.

\section{Stable Equilibriums of Firms}

In this section, we're going to introduce the equilibrium, and Bayesian Nash equilibrium is used to analyze the model. Meanwhile, to avoid the complexity to blur the discussion, we based on the results of pure strategy. And the conditions of equilibrium are listed in Table 2.

Let's draw figures to portray the areas of the Bayesian Nash equilibriums. Let $w$ be the horizontal axis and $f$ be the vertical axis. Figure 1 shows the equilibriums as $a>c$. We have two lines to distinguish the areas of the Bayesian Nash equilibriums, line $L_{1}$ and $L_{2}$.

$$
L_{1}: f=w+a-c \quad L_{2}: f=\frac{w}{1-p}+a-c-\frac{p z}{1-p} .
$$

\begin{tabular}{|c|c|c|c|}
\hline & & \multicolumn{2}{|c|}{ Player 2} \\
\hline \multirow{3}{*}{ Player 1} & & Comply & Defect \\
\hline & Comply & ${ }^{\left(1^{\prime}\right)} A_{1}, A_{2}$ & (3) $C_{1}, C_{2}$ \\
\hline & Defect & (2) $B_{1}, B_{2}$ & (4) $D_{1}, D_{2}$ \\
\hline
\end{tabular}

And the point $e(=(z, z+a-c))$ is the intersection of two lines, under $a>c$. Here we show the Figure 1 as below.

Let's talk about another situation under different condition. And Figure 2 is the situation when $a<c$ and

Table 1. Normal form of the cartel game.

Table 2. The Bayesian Nash equilibrium of model.

\begin{tabular}{cc}
\hline Equilibrium & Condition of Equilibrium \\
\hline${ }^{\left({ }^{\prime}\right)}\left(A_{1}, A_{2}\right)$ & $f \geq w+a-c$ \\
$\left(^{\left({ }^{\prime}\right)}\left(B_{1}, B_{2}\right)\right.$ & $f \in\left[\frac{w}{1-p}+a-c-\frac{p z}{1-p}, w+a-c\right]$ \\
${ }^{\left({ }^{\prime}\right)}\left(C_{1}, C_{2}\right)$ & $f \in\left[\frac{w}{1-p}+a-c-\frac{p z}{1-p}, w+a-c\right]$ \\
(4) $^{\prime}\left(D_{1}, D_{2}\right)$ & $f \leq \frac{w}{1-p}+a-c-\frac{p z}{1-p}$ \\
\hline
\end{tabular}

$a-c=-z$. Because of $a-c=-z$, the horizontal axis value of $e$ is zero. There are also tow lines, $L_{1}$ and $L_{2}$, to distinguish the equilibrium areas. And $e$ is $(z, 0)$. Under $a-c=-z$, there is no equilibrium area for (2') and ( $\left.3^{\prime}\right)$. That is to say, there is no circumstance for two firms that one firm complies with the cartel agreement and the other one defects. Here we show the Figure 2 as below:

And what we want to focus on is the two firms' stable equilibrium. When $f$ is large, it's easier to exist the equilibrium of being a cartel because of firms don't want to take any risk of being punished; on the contrary, when $f$ is small enough, the equilibrium of both two firms' defecting strategies would happen more likely. The Bayesian Nash equilibriums may be summarized as the first two propositions in the following.

[Proposition 1] When $f \geq \max [w+a-c,(w-p z) /(1-p)+a-c],\left(1^{\prime}\right)$ is an unique Bayesian Nash equilibrium for two firms to be a cartel.

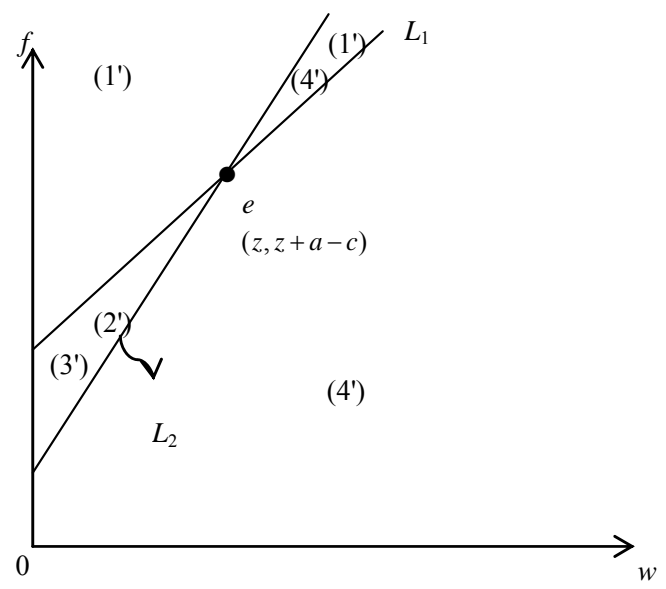

Figure 1. $a>c$.

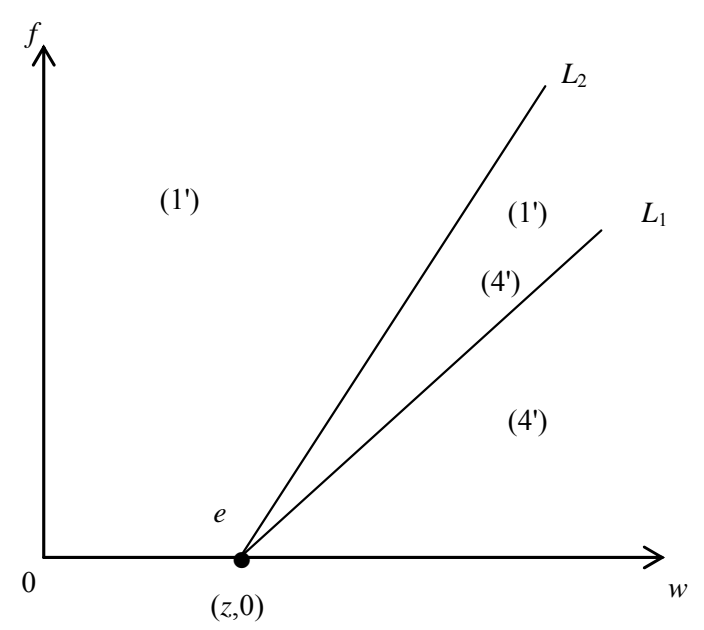

Figure 2. $a-c=-z$ \& $a<c$. 
[Proposition 2] When

$f \in[w+a-c,(w-p z) /(1-p)+a-c]$, there are two equilibrium ( $\left.1^{\prime}\right)$ and (4') in this area.

When the two (1') and (4') are the equilibriums at the same time, we call that coordinate game. Generally speaking, it depends on the value of $A_{1}$ and $D_{1}$ to know which one is easier to be the equilibrium. As $f<[(1-p)(a+z)+w] /(2-p)-c$, then $D_{1}>A_{1},\left(4^{\prime}\right)$ would be the equilibrium more easily. On the contrary, it's more likely to exist the equilibrium (1').

[Proposition 3] When $a-c \leq-z$, it won't exist the equilibrium of (2') and (3').

If firms are aware of their own benefit is too small for them to confess to the authority, they have no incentive to defect. Hence, there are no equilibrium of (2') and (3'). And it is shown in Figure 2.

Besides, the legitimacies of cartels in Taiwan and in America (as well as European countries) are different. In Taiwan, if firms don't apply to the authorities, the actions of collusion would be recognized as illegal definitely. But in America or in Europe, the legitimacy depends on the effect after the firms have already formed the cartels. Therefore, we have to compare the two different mechanisms under the same condition. We assume that collusion is the most efficient strategy first, which means the value of two firms' welfare plus consumers' welfare would be the highest of four possible equilibrium values. Under the American or European laws, even the firms don't apply to the cartel offices in advance, the probability of being processed by the cartel offices, $p$, would still be regarded as zero. However in Taiwan, if firms don't apply for the permission of cartels to the authorities beforehand, $p$ would be definitely 1 . When $p=0$, firms' equilibrium payoffs become $\pi+c$ under the antitrust laws of America or Europe. So there is no limitation for firms of being a cartel at all; When $p=1$, it must fulfill the condition that $f \geq w+a-c$ at least to form cartels. Hence, comparing the two kinds of different mechanisms, cartels are easier to exist in America (or in Europe) than in Taiwan. And here above is proposition 4.

[Proposition 4] It's easier to exist cartels in America or Europe than in Taiwan.

\section{Conclusions}

In this paper, we used a game-theoretical model to analyze the equilibriums of two firms' strategies in a cartel. And the amount of fine payment is the key factor to affect two firms' equilibrium.

The actions of firms being a cartel would be allowed if it is good for the whole society. That is to say, the antitrust authorities will not interfere too much to forbid cartels all the time. However in Taiwan, antitrust authorities will not permit a cartel absolutely if firms do not make applications in advance. The conclusion is that cartels are easier to appear in America (or Europe) than in Taiwan. Hence, how to enact the antitrust laws becomes a very important issue to the cartel office.

This paper is surely to provide a point of view for antitrust authorities to set the policies of leniency programs. And it may intrigue more people to study about this issue in the future and then the antitrust authorities would control the actions of cartels more effectively.

\section{REFERENCES}

[1] U. Blum, N. Steinat and M. Veltins, "On the Rationale of Leniency Programs: A Game-theoretical Analysis," European Journal of Law and Economics, Vol. 25, No. 3, 2008, pp. 209-229. doi:10.1007/s10657-008-9046-x

[2] M. Motta and M. Polo, "Leniency Programs and Cartel Prosecution," International Journal of Industrial Organization, Vol. 21, No. 3, 2003, pp. 347-379. doi:10.1016/S0167-7187(02)00057-7

[3] C. Ellis and W. Wilson, "Cartels, Price-fixing, and Corporate Leniency Policy: What Doesn't Kill Us Makes Us Stronger," University of Oregon, Eugene, 2003.

[4] G. Spagnolo, "Divide et Impera - Optimal Deterrence Mechanisms against Cartels (and Organized Crime)," FEEM Working Paper, Milano, 2004.

[5] C. Aubert, P. Rey and W. E. Kovacic, "The Impact of Leniency and Whistle-Blowing Programs on Cartels," International Journal of Industrial Organization, Vol. 24, No. 6, 2006, pp. 1241-1266. doi:10.1016/j.ijindorg.2006.04.002

[6] A. Chavda and M. Jegers, "The Effects of Leniency Programs and Fines on Cartel Stability," Metroeconomica, Vol. 58, No. 2, 2007, pp. 231-243. doi:10.1111/j.1467-999X.2007.00266.x 